\title{
Child and parental adaptation to pediatric stem cell transplantation
}

\author{
C. M. Jantien Vrijmoet-Wiersma • \\ Annemarie M. Kolk • Martha A. Grootenhuis • \\ Emmelien M. Spek • Jeanine M. M. van Klink • \\ R. Maarten Egeler • Robbert G. M. Bredius • \\ Hendrik M. Koopman
}

Received: 11 July 2008 / Accepted: 17 November 2008 / Published online: 3 December 2008

(C) The Author(s) 2008. This article is published with open access at Springerlink.com

\begin{abstract}
Goals of work Allogeneic pediatric stem cell transplantation $(\mathrm{SCT})$ is a very intensive treatment with a high mortality and morbidity. The objectives of this study were to assess the (1) self- and proxy-reported health-related quality of life (HRQoL) compared to a norm group, (2) levels of parenting stress compared to a norm group, (3)
\end{abstract}

\author{
C. M. J. Vrijmoet-Wiersma $(\bowtie) \cdot$ R. M. Egeler $\cdot$ R. G. M. Bredius \\ Pediatric Department, Leiden University Medical Center, \\ P.O. Box 9600, 2300 RC Leiden, The Netherlands \\ e-mail: c.m.j.vrijmoet-wiersma@lumc.nl \\ R. M. Egeler \\ e-mail: r.m.egeler@lumc.nl \\ R. G. M. Bredius \\ e-mail: r.g.m.bredius@lumc.nl
}

A. M. Kolk $\cdot$ E. M. Spek · J. M. M. van Klink

Department of Clinical Psychology, University of Amsterdam,

Roetersstraat 15 ,

1018 WB Amsterdam, The Netherlands

A. M. Kolk

e-mail: A.m.m.kolk@uva.nl

E. M. Spek

e-mail: emspek@hotmail.com

J. M. M. van Klink

e-mail: jeaninevanklink@gmail.com

M. A. Grootenhuis

Psychosocial Department, Academic Medical Center, P.O. Box 22660, 1100 DD Amsterdam, The Netherlands

e-mail: m.a.grootenhuis@amc.uva.nl

H. M. Koopman

Medical Psychology, Leiden University Medical Center, P.O. Box 9555, 2300 RB Leiden, The Netherlands

e-mail: h.m.koopman@lumc.nl differences in HRQoL and parenting stress pre- and postSCT, and (4) effect of child age and parenting stress on selfand proxy-reported HRQoL pre- and post-SCT.

Materials and methods Pre- and on average 10 months post-SCT, 21 children and adolescents and their parent(s) completed questionnaires on HRQoL and the mothers completed a measure of parenting stress.

Main results Post-SCT, home functioning, physical functioning, and total HRQoL scores were lower than the norm group. We found stable HRQoL scores over time with the exception of the domain home functioning, which was rated lower post-SCT than pre-SCT. Parents reported lower HRQoL scores than the children pre- and post-SCT and younger children experienced better HRQoL than older children. Parenting stress was higher post-SCT than pre$\mathrm{SCT}$ and high levels of parenting stress were predictive of poor parental ratings of child HRQoL post-SCT.

Conclusions Ongoing psychosocial assessment post-SCT is necessary to target children with a lowered HRQoL and parents who experience elevated parenting stress who may be in greater need of more supportive care.

Keywords Health-related quality of life - Pediatric SCT . Parenting stress

\section{Introduction}

Children undergoing stem cell transplantation (SCT) are subjected to a far-reaching, life-threatening, and rare medical procedure only carried out about 60 times per year in The Netherlands. Even though the transplant procedure has become much more sophisticated and, as a consequence, mortality rates have decreased [9], SCT still 
represents a severe stressor for the child and family. SCT is often the last possibility after a long-term treatment. The lengthy hospitalization in isolation, the physical discomfort, the uncertainty about the outcome, and the fear of death are stressors associated with this treatment [3335]. Outcomes may vary from cure (and normality) to chronic graft-versushost disease (GVHD), relapse, or even death $[6,15]$. Many SCT survivors report long-term physical sequelae like fatigue [29], growth retardation and impaired pubertal development $[5,28]$, pain $[20,28]$, liver complications, and decreased lung functioning [38].

An SCT inevitably has an impact on how physical, emotional, and social functioning is perceived by the child and family; in other words, on the health-related quality of life (HRQoL). HRQoL can be defined as a combination of the experienced health status (e.g., the assessment by a person of his or her own health functioning) and the affective response to problems with respect to this health status [41]. Most HRQoL research in SCT patients has been conducted with adults. In the majority of the studies, a negative impact on the HRQoL evaluation in a proportion of adults has been found $[9,11,40]$, often due to functional limitations and somatic symptoms [9] and to concerns about relapsing $[2,4]$.

However, an extensive review of studies involving pediatric patients [43] showed that the majority of both children and their parents indicated an improved HRQoL with time [6], rated the child's HRQoL as "good" post-SCT $[19,20,28]$, or even reported a high quality of life (QoL) post-SCT $[3,30]$. The reported high HRQoL scores in these studies could be explained in terms of "response shift": as a result of health changes, an individual may undergo changes in internal standards, values, or conceptualization of HRQoL [37]. Children undergoing SCT might use response shift as a coping mechanism to accommodate themselves to their disease and health status. Furthermore, children with serious illness such as cancer or sickle cell anemia have been found to show a remarkable "hardiness" and a lack of psychopathology despite multiple challenges [31].

Differences between self-reported and parent proxyreported HRQoL have been addressed by several authors (e.g., $[10,12,16,41])$. Parent-child agreement seems to be influenced by the child's age with older age predicting greater differences, health status (a higher agreement has been found between parents and chronically sick children than between parents and healthy children), the types of the HRQoL domains investigated (i.e., a higher agreement for physical aspects of health versus emotional aspects) [12, 14], parental QoL [17], and maternal affective disturbances [6, 13]. To our knowledge, the influence of parenting stress on proxy-rated HRQoL has not been studied so far.

The current study was designed to assess the (1) selfand proxy-reported HRQoL compared to a norm group, (2) levels of parenting stress compared to a norm group, (3) differences in HRQoL and parenting stress pre- and postSCT, and (4) effect of child age and parenting stress on selfand proxy-reported HRQOL pre- and post-SCT.

\section{Materials and methods}

Study design and procedure

The study had a prospective design pretest (i.e., preadmission for SCT) and posttest. All consecutive patients receiving SCT in the Leiden University Medical Center (LUMC) from February 2004 to May 2005 and their parents were eligible for the study. Excluded were patients younger than 3 years old and patients and parents who did not speak Dutch sufficiently to fill in the questionnaires. After informed consent was obtained from parents and children older than 8 years, they were asked to complete a booklet of self-report questionnaires at home 2 weeks prior to admission to SCT.

At least 2 months post-SCT, letters were sent to children and parents briefly describing the follow-up study asking them to complete the same questionnaires again, supervised during a home visit. The Ethical Committee and the Department of Pediatrics of the LUMC approved the study.

\section{Measures}

Dutch children's AZL/TNO quality of life questionnaire (DUX 25)

This generic questionnaire was used to asses how children evaluate HRQoL in their day-to-day functioning [22]. There are four domains: family, physical, emotional, and social functioning. Besides, a total HRQoL score can be obtained. An example of an item is: "I often feel...." Answers can be given on a five-point Likert scale, visualized as smileys ranging from very happy to very sad (score 5-1). Items scores are converted to a $1-100$ scale with higher scores representing a higher QoL. The DUX 25 consists of a child form (CF) and a parent form (PF). Both forms were found to be sufficiently internally consistent (i.e., reliable) in this sample (CF: $\alpha=0.74-0.90$, PF: $\alpha=0.79-0.88)$. Scores were compared with a norm group drawn from the total pool of 935 children aged $8-18$ years [21].

The reason we chose the DUX 25 is that this instrument is user-friendly because of the smileys and the limited length of the questionnaire and because it measures the affective appraisal of daily functioning instead of solely assessing functional status, like many other QOL measures do. 


\section{Parenting stress index}

The Dutch version of the parenting stress index (PSI) [1], named NOSI [9], was used to measure parenting stress. The PSI consists of 123 items tapping child and parent characteristics. Child characteristics are measured in six subscales, e.g., distractibility/hyperactivity, adaptability, positive reinforcement, demanding, mood, and acceptability. Parent characteristics are measured in seven subscales, i.e., competence, social isolation, attachment, health, role restriction, depression, and marital relationship. Validity and reliability of the PSI are sufficient [8]. The PSI has been used extensively to assess the parent-child dyad in a variety of clinical and research settings, e.g., [42]. Because the PSI is a lengthy questionnaire, we asked only one parent (i.e., the mother) to fill it in. The reliability of the total scale in this study was 0.96 .

\section{Demographic and disease-related characteristics}

Age at first measurement, gender, ethnicity, disease-related characteristics, length of time since SCT, and the indication of SCT/diagnosis were obtained from the children's medical files. Parental age and gender were recorded as well.

\section{Statistical analysis}

The Statistical Package for Social Sciences (SPSS) version 14 was used for all analyses. One-way analysis of variance was used to compare HRQoL scores to a norm group. We expected HRQoL of patients to be comparable to the norm group post-SCT. Analyses of variance for repeated measures and Tukey post hoc correction were applied to compare pre- and post-HRQoL scores. Independent $t$ tests were used to compare HRQoL and parenting stress scores to norm groups. Pearson correlations were used for the associations between the child and proxy evaluations of HRQoL and to examine the association of age and length of time passed since SCT with post-HRQoL; $t$ tests were also applied to investigate the role of length of time since SCT. Furthermore, Pearson correlations were used for finding associations between parenting stress and pre- and postproxy HRQoL reports.

Overall, significance was set at $\alpha$ of 0.05 . We accounted for multiple testing by using the Bonferroni correction.

\section{Results}

Participants

In the study period of 14 months, 37 pediatric SCTs were carried out in the LUMC. Of the 28 eligible families approached, 24 agreed to participate (86\%). Two families refused to participate because they felt "too overwhelmed." Two nonnative speaking parents refused participation because of language problems not foreseen by the research team. Three children did not want to fill in the questionnaires, but their parents did. The children $(n=21)$, of which 18 were males $(85 \%)$, were diagnosed with a variety of malignant $(n=13)$ and nonmalignant $(n=8)$ diseases. The average age of the children pre-SCT was 11 years (Table 1). Nonparticipants did not differ from participants with respect to age, gender, and primary diagnosis. However, non-Dutch speakers were overrepresented in this group (57\% versus $10 \%$ ) and this might have influenced our results.

Pre-SCT Two patients were too ill to complete the questionnaires and four children were too young to complete the questionnaires themselves, but their parents filled in the questionnaires. In total, 15 children and 31 parents of 21 children (19 mothers and 12 fathers) completed the measures pre-SCT.

Post-SCT (range 2 to 16 months post-SCT, mean 10 months, $S D$ 4.7) Due to a tight time schedule of the research students involved in the project, the study had to take place in a limited period of time. This has resulted in a relatively large variability in time since SCT between the participants. Between the pre-SCT and post-SCT assessment, three patients out of the total 21 potential participants died. The parents of these children were not asked to participate in the follow-up assessment. One of the patients could not

Table 1 Descriptive information study sample

\begin{tabular}{lccc}
\hline Characteristics & Mean & SD & Range \\
\hline Patient ( $n=21$ ) & & & \\
$\quad$ Age at first assessment (years) & 11 & 4.8 & $3.7-18.9$ \\
Time since SCT (months) & 10 & 4.4 & $2-16$ \\
Sex & 18 & $85 \%$ & \\
$\quad$ Male & & & \\
$\quad$ Country of origin & 19 & $90 \%$ & \\
$\quad$ Dutch & 2 & $10 \%$ & \\
$\quad$ Non-Dutch & & & \\
Diagnoses & 9 & $43 \%$ & \\
$\quad$ Malignant: leukemia (AML, ALL) & & & \\
Nonmalignant & 10 & $47 \%$ & \\
$\quad$ Blood disease (SAA, MDS) & 2 & $10 \%$ & \\
$\quad$ Immune disease (SCID) & & & \\
Parent ( $n=31$ ) & 42 & 5.5 & $35-59$ \\
$\quad$ Age at first assessment (years) & & & \\
Sex & 12 & 39 & \\
$\quad$ Male &
\end{tabular}

$S C T$ stem cell transplantation, $A M L$ acute myeloid leukemia, $A L L$ acute lymphoblastic leukemia, $S A A$ severe aplastic anemia, $M D S$ myeloid dysplastic syndrome, SCID severe combined immune deficiency syndrome 
participate in the follow-up study due to medical complications. One family was lost to follow-up. In total, 16 children and 31 parents of 21 children (19 mothers and 12 fathers) completed the assessment measures post-SCT. Fourteen children filled in the questionnaires both preand post-SCT. Because of the low number of girls in our study group and since boys and girls did not differ in age, time since SCT and severity of complications during and post-SCT, they were analyzed as one group.

Health-related quality of life of pediatric SCT patients

Norm group Compared to the age- and gender-matched norm group of healthy children (self-report) pre-SCT, HRQoL scores were comparable on all domains. However, post-SCT, self-reported HRQoL was significantly lower on the domains physical functioning $[F(1,44)=2.284 ; p=$ $0.027]$, home functioning $[F(1,45)=2.40 ; p=0.03]$, and total HRQoL $[F(1,43)=2.18 ; p=0.035]$ (see Fig. 1). Compared to the norm group, parents of SCT patients rated their child's HRQoL significantly lower on all four domains and on total HRQoL.

Pre- and post-HRQoL scores There was an effect of time for home functioning (i.e., the perception of the child's well-being at home) $[F(1,24)=6.22 ; p=0.02]$. The child, mother, and father ratings of home functioning post-SCT were lower than the ratings of home functioning pre-SCT (see Fig. 1). The evaluation of physical functioning, emotional functioning, and social functioning remained stable, just as the total HRQoL scores (see Fig. 1).

Child-proxy (parent) agreement There was an effect of group (child, mother) for physical functioning $[F(2,24)=$ $3.79 ; p=0.04]$, home functioning $[F(1,24)=10.74$; $p=0.001]$, and emotional functioning $[F(1,24)=4.03$; $p=0.03]$. Mothers reported lower scores than the children on all three domains (see Fig. 1), whereas the ratings of the fathers only differed with the child ratings on the home functioning domain. Mothers and fathers did not differ significantly in their HRQoL ratings.

\section{Parenting stress}

Norm group Compared to the norm group of the PSI, mothers reported to have higher parenting stress levels than parents of healthy children post-SCT, but not pre-SCT. Significantly lower scores compared to the norm group was

Fig. 1 HRQoL pre- and post-SCT. Lower scores refer to lower HRQoL
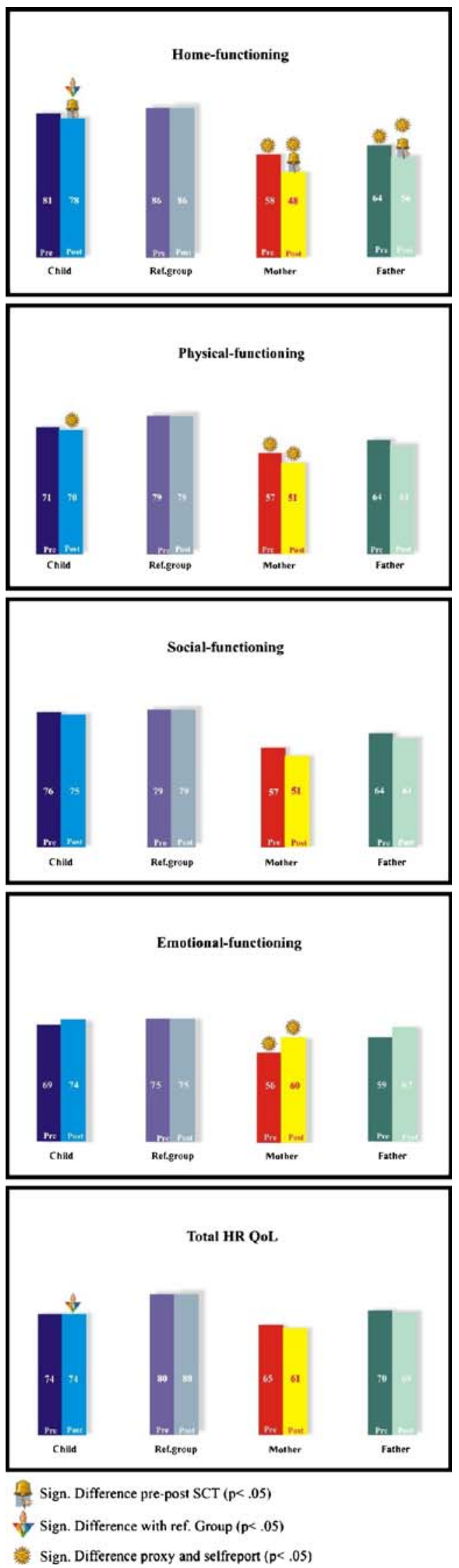

Lower scores refer to lower HRQoL 
seen post-SCT on the subscale "competence" (the feelings of competence the parent gets from parenting this child). Scores on the other scales were not statistically different from the norm group (Table 2).

Pre- and post-parenting stress scores Thirteen mothers completed the PSI both pre- and post-SCT. Most of the PSI domains remained stable over time. However, the subscale "demanding" and total parenting stress were significantly higher post-SCT than pre-SCT, meaning stress accumulated over time (Table 2).

\section{Child age}

The age of the children at first measurement was associated with the children's self-reported HRQoL pre-SCT: younger children reported higher HRQoL scores [Pearson correlation coefficient $=-0.55 ; p=0.03]$. Pre-SCT, child age was also associated with proxy-reported HRQoL [Pearson correlation coefficient $=-0.47 ; p=0.02]$ (Table 3). Post$\mathrm{SCT}$, child age was not associated with self- or proxyreported HRQoL.

The impact of parenting stress on proxy-reported HRQoL

The PSI subscale "demanding" was significantly related to pre- and post-proxy HRQoL reports. No other domains of the PSI were correlated to pre-SCT proxy HRQoL report. However, post-SCT, Pearson correlations revealed significant associations between several domains of parenting stress and HRQoL: low adaptability, a lack of positive reinforcement, mood swings, problems related to accep- tance, feeling incompetent as a parent, parents' own health, role restriction, parental depressive feelings, and dissatisfaction with the marital relationship were all associated with lower proxy-reported HRQoL scores (see Table 3). Strangely, there was no association between total parenting stress and proxy ratings of HRQoL post-SCT.

\section{Discussion}

On average 10 months after SCT, children and adolescents reported low HRQoL scores compared to a norm group of healthy peers, especially with relation to functioning at home. Parents rated their children's HRQoL significantly lower both pre- and post-SCT compared to the children themselves and compared to a norm group of healthy peers. As expected and in line with other studies [33,34], younger children experienced better HRQoL than older children and adolescents. Total parenting stress levels were significantly higher post-SCT than pre-SCT. An important predictor of proxy-rated HRQoL was found in the child's demandingness perceived by the parents, assessed before and after admittance for SCT.

The low post-SCT HRQoL ratings we found are in contrast with results reported in several other studies $[6,15$, $28]$ in which an improved HRQoL was found after 6 months or more. One explanation for this difference could be the number of assessments done in some of these studies [15, 34]. Multiple assessments can generate higher scores: being involved in a trial can create a "Hawthorne effect" because of the extra attention that is given to a person [7]. Another explanation for the discrepancy could be the length of time passed since transplantation. We assessed HRQoL on

Table 2 Parenting stress scores (mothers) pre- and post-SCT

\begin{tabular}{|c|c|c|c|}
\hline PSI subscales & Pre-SCT, mean (SD), $n=13$ & Post-SCT, mean (SD), $n=19$ & Norm group, mean (SD), $n=161$ \\
\hline Distractibility & $33.3(7.2)$ & $32.5(7.5)$ & $30.6(11.0)$ \\
\hline Adaptability & $28.1(6.8)$ & $28.4(10.8)$ & $32.3(8.6)$ \\
\hline Reinforces parent & $19.2(3.6)$ & $22.0(5.6)^{*}$ & $17.3(5.2)$ \\
\hline Demanding & $21.5(9.3)$ & $25.7(13.6)$ & $20.8(7.3)$ \\
\hline Mood & $20.1(5.4)$ & $22.8(8.8)$ & $21.7(7.6)$ \\
\hline Acceptance & $18.9(5.7)$ & $22.3(8.8)$ & $22.6(7.6)$ \\
\hline Competence & $33.2(7.8)$ & 34. $2(7.3)^{*}$ & $29.4(9.1)$ \\
\hline Social isolation & $10.2(4.0)$ & $12.5(10.6)$ & $13.5(6.8)$ \\
\hline Attachment & $10.4(3.5)$ & $10.3(4.1)$ & $12.3(4.3)$ \\
\hline Health & $13.1(5.7)$ & $14.8(6.7)$ & $13.6(5.0)$ \\
\hline Role restriction & $15.5(6.5)$ & $16.5(7.4)$ & $14.3(5.8)$ \\
\hline Depression & $23.1(10.4)$ & $24.8(10.9)$ & $26.8(9.6)$ \\
\hline Marital relation & $13.6(6.1)$ & $13.7(6.5)$ & $13.5(6.8)$ \\
\hline Total PSI & $259.8(67.1)$ & $277.3(89.1)^{*}$ & $266.5(66.9)$ \\
\hline
\end{tabular}

Higher scores refer to more problems. In bold, significant difference with norm group. In italics, significant difference between pre- and post-SCT $P S I$ parenting stress index

$* p \leq 0.05$ 
Table 3 Bivariate correlations between independent variables with proxy-reported HRQoL pre- and post-SCT

\begin{tabular}{|c|c|c|c|c|}
\hline & \multicolumn{2}{|c|}{ HRQoL pre-SCT } & \multicolumn{2}{|c|}{ HRQoL post-SCT } \\
\hline & \multicolumn{2}{|l|}{$n=13$} & \multicolumn{2}{|l|}{$n=21$} \\
\hline & $r$ & $p$ & $r$ & $p$ \\
\hline \multicolumn{5}{|l|}{ Demographics } \\
\hline Time since SCT & - & - & 0.26 & n.s. \\
\hline Child age & $-0.47^{*}$ & 0.02 & 0.17 & n.s. \\
\hline \multicolumn{5}{|l|}{ PSI subscales (mothers) } \\
\hline Distractibility & 0.32 & n.s. & $-0.45^{*}$ & n.s. \\
\hline Adaptability & -0.33 & n.s. & $-0.64 *$ & 0.01 \\
\hline Reinforces parent & 0.03 & n.s. & $-0.61^{*}$ & 0.01 \\
\hline Demanding & $-0.56^{*}$ & 0.04 & $-0.71 *$ & 0.01 \\
\hline Mood & -0.35 & n.s. & $-0.71 *$ & 0.01 \\
\hline Acceptance & -0.22 & n.s. & $-0.67 *$ & 0.01 \\
\hline Competence & -0.37 & n.s. & $-0.51^{*}$ & 0.02 \\
\hline Social isolation & -0.48 & n.s. & -0.33 & n.s. \\
\hline Attachment & -0.21 & n.s. & -0.41 & n.s. \\
\hline Health & 0.01 & n.s. & $-0.58^{*}$ & 0.01 \\
\hline Role restriction & -0.10 & n.s. & $-0.61^{*}$ & 0.01 \\
\hline Depression & -0.30 & n.s. & $-0.64 *$ & 0.01 \\
\hline Marital relation & 0.03 & n.s. & $-0.64 *$ & 0.01 \\
\hline Total parenting stress & -0.34 & n.s. & -0.38 & n.s. \\
\hline
\end{tabular}

n.s. not significant

$* p \leq 0.05$

average 10 months post-SCT, which is still a more or less active treatment period, whereas other researchers reported improved HRQoL [19] using an interval of 3 years [40] or 5 years posttransplantation [11]. It is possible that our follow-up period post-SCT was too short to detect any time effects and needs to be extended in further studies.

Differences in child and proxy evaluations of HRQoL have been reported by many other researchers [10, 14, 32]. A first explanation could be that parent and child reports of HRQoL are based on different perspectives: the child reports on his or her subjective personal situation, whereas parents can only infer from observations and communication with the child [23]. Secondly, children are usually more focused on "here and now," whereas parents are more concerned with their child's well-being and HRQoL in the future [16]. This generates different perspectives on the same issues.

Furthermore, parental emotional functioning and the way parents perceive stressors associated with a child's SCT may negatively affect the evaluations of their child's HRQoL [13, 33]. Research has shown that parents of children undergoing SCT can suffer from posttraumatic stress symptoms [25, 27], depression [6, 26], distress $[35,39]$, and anxiety [6, 25]. Maternal post-SCT anxiety and depression scores have been found to correlate with their children's QoL ratings at 6 months post-SCT [6]. It has been suggested that maternal psychological problems could be a result of their children's ongoing medical problems and subsequent reduced QoL [6]. However, the opposite could also be true: parents who experience more stress could be less optimistic in general and tend to see their children's situation in their own frame of mind [16].

In our study, parenting stress was significantly related to the appreciation of the child's HRQoL, both pre- and, especially, post-SCT. Specifically, pre-SCT, the degree to which parents perceived the child to be demanding (e.g., crying, clinging, asking for help) influenced parental HRQoL ratings. Post-SCT, significant associations were found between child demandingness, parental health, role restriction, a lack of reinforcement from the child, and marital stress on the one hand and proxy-rated HRQoL on the other. Parents felt significantly less competent than parents of healthy children, post-SCT. This may indicate that post-SCT, parents are faced with more stress concerning parent-child interaction and marital functioning than pre-SCT. The strain of caring for the child after discharge adds to the already present stressors of parents. Furthermore, the fear of relapse remains and makes parents vulnerable to stress and could be reflected in the lower rating of the domain "home functioning" by both parents and children, post-SCT. Given the strong relationship between maternal ratings of the child's functioning with ratings of her own functioning, ideally dyadic ratings of both parents and children should be used as much as possible to determine pediatric HRQoL in clinical settings [14, 36].

The present study has a number of limitations that should be taken into account. Since our single-center study sample contained a relatively small number of children and parents, there is a chance of missing important relationships or of detecting significant differences even though they may not exist. Due to high mortality and morbidity rates in this patient group, it is very difficult to collect large samples, especially in a country as small as The Netherlands. In addition, our group of children contained more boys than girls and our parent group contained more mothers than fathers. We analyzed fathers and mothers of the same children together, which can cause bias. We only assessed parenting stress in mothers, which limits the generalization of results to all parents. Furthermore, there was a large variance in age and length of time since SCT within the child group. Comparing children with heterogeneous underlying diagnoses (malignant or nonmalignant) can also have disadvantages. A recent study by Löf et al. [24] showed that parents of children with leukemia rated their child's HRQoL lower than parents of children transplanted for nonmalignant diseases. Children with leukemia reported more problems in the psychosocial area than children with nonmalignant diseases.

Due to the small number of participants, we were unable to study other important factors that are of influence on 
HRQoL, such as clinical factors (primary diagnosis, risk of relapse at SCT, posttransplant complications including acute and chronic GVHD) and sociodemographic characteristics of the participants. Finally, we assessed HRQoL and parenting stress with generic questionnaires. Making use of disease-related and/or disease-specific questionnaires could provide more specific insight on the effects of SCT on the child's HRQoL and on parental stress. Other areas of interest like self-esteem and parental QoL could also be studied with the use of more specific instruments.

\section{Conclusions}

Since SCT is of very low incidence and morbidity and mortality rates are high, research involving multiple institutions should be the primary setting for studying patients that are homogeneous with regard to age, diagnosis, time since SCT, and the presence of late effects like GVHD. Larger time intervals and multiple assessments are needed to study the process of HRQoL and parenting stress in time in more depth. Proxy data can provide significantly different information than self-reported data, especially for adolescents $[10,18]$; hence, consulting the child's own perception next to the parent's view when measuring HRQoL is necessary [14].

We strongly recommend ongoing psychological assessment pre-and post-SCT in order to target children who report lowered HRQoL scores pre-SCT and/or post-SCT and parents who experience high levels of parenting stress who may be in greater need of preventive interventions or more supportive care, not only during the active SCT phase, but also in the months following discharge.

Acknowledgements We would like to thank all the participating families for their willingness to cooperate and we would like to thank Hanny Bakker-Steeneveld for assisting with the data management and Jan Feenstra for his help with the figure.

Open Access This article is distributed under the terms of the Creative Commons Attribution Noncommercial License which permits any noncommercial use, distribution, and reproduction in any medium, provided the original author(s) and source are credited.

\section{References}

1. Abidin RR (1995) Parenting stress index, 3rd edn. Psychological Assessment Resources, Odessa, FL

2. Andrykowski MAA, Bishop MM, Hahn EA, Cella DF, Beaumont JL, Brady MJ et al (2005) Long-term health-related quality of life, growth, and spiritual well-being after hematopoietic stem-cell transplantation. J Clin Oncol 23(3):599-608 doi:10.1200/ JCO.2005.03.189

3. Badell I, Igual L, Gomez P, Bureo E, Ortega JJ, Muñoz A et al (1998) Quality of life in young adults having received a BMT during childhood: a GETMON study. Grupo Español de Tras- plante de Médula Osea en el Niño. Bone Marrow Transplant 21 (Suppl. 2):S68-S71

4. Baker F, Wingard JR, Curbow BA, Zabora J, Jodrey D, Fogarty L et al (1994) Quality of life of bone marrow transplant long-term survivors. Bone Marrow Transplant 13(5):589-596

5. Bakker B, Oostdijk W, Geskus RW, Stofvis-Brantsma WH, Vossen JM, Wit JM (2006) Patterns of growth and body proportions after total-body irradiation and hematopoietic stem cell transplantation during childhood. Pediatr Res 59(2):259-264 doi:10.1203/01.pdr.0000199550.71887.ba

6. Barrera M, Boyd-Pringle LA, Sumbler K, Saunders F (2000) Quality of life and behavioral adjustment after pediatric bone marrow transplantation. Bone Marrow Transplant 26(4):427-435 doi:10.1038/sj.bmt.1702527

7. Beenakker EAC, Fock JM, Van Tol MJ, Maurits NM, Koopman HM, Brouwer et al (2005) Intermittent prednisone therapy in Duchenne muscular dystrophy: a randomized controlled trial. Arch Neurol 62(1):128-132 doi:10.1001/archneur.62.1.128

8. Brock de AJLL, Vermulst AA, Gerris JRM, Abidin RR (1992) Handleiding Nijmeegse Ouderlijke Stress Index. Swets \& Zeitlinger, Lisse

9. Broers S, Kaptein AA, Le Cessie S, Fibbe W, Hengeveld MW (2000) Psychological functioning and quality of life following bone marrow transplantation: a 3-year follow-up study. J Psychosom Res 48 (1):11-21 doi:10.1016/S0022-3999(99)00059-8

10. Chang PC, Yeh CH (2005) Agreement between child self-report and parent proxy-report to evaluate quality of life in children with cancer. Psychooncology 14(2):125-134 doi:10.1002/pon.828

11. Chiodi S, Spinelli S, Ravera G, Petti AR, van Lint MT, Lamparelli $\mathrm{T}$ et al (2000) Quality of life in 244 recipients of allogeneic bone marrow transplantation. Br J Haematol 110(3):614-619 doi:10.1046/j.1365-2141.2000.02053.x

12. Cremeens J, Eiser C, Blades M (2006) Factors influencing agreement between child self-report and parent proxy-reports on the Pediatric Quality of Life InventoryTM 4.0 (PedsQLTM) generic core scales. Health Qual Life Outcomes 4(1):58 doi:10.1186/1477-7525-4-58

13. Davis E, Davies B, Waters E, Priest N (2008) The relationship between proxy reported health-related quality of life and parental distress: gender differences. Child Care Health Dev 36(6):830-837

14. Eiser C, Morse R (2001) Can parents rate their child's healthrelated quality of life? Results of a systematic review. Qual Life Res 10(4):347-357 doi:10.1023/A:1012253723272

15. Felder-Puig R, di Gallo A, Waldenmair M, Norden P, Winter A, Gadner H et al (2006) Health-related quality of life of pediatric patients receiving allogeneic stem cell or bone marrow transplantation: results of a longitudinal, multi-center study. Bone Marrow Transplant 38(2):119-126 doi:10.1038/sj.bmt.1705417

16. Forinder U, Lof C, Winiarski J (2006) Quality of life following allogeneic stem cell transplantation, comparing parents' and children's perspective. Pediatr Transplant 10(4):491-496 doi:10.1111/j.1399-3046.2006.00507.x

17. Goldbeck L, Melches J (2005) Quality of life in families of children with congenital heart disease. Qual Life Res 14(8):19151924 doi:10.1007/s11136-005-4327-0

18. Guyatt GH (1999) Measuring health-related quality of life in childhood cancer: lessons from the workshop. Int J Cancer Suppl 12:143-146 doi:10.1002/(SICI)1097-0215(1999)83:12+<143:: AID-IJC25>3.0.CO;2-V

19. Helder DI, Bakker B, de Heer P, van der Veen F, Vossen JMJJ, Wit JM et al (2004) Quality of life in adults following bone marrow transplantation during childhood. Bone Marrow Transplant 33(3):329-336 doi:10.1038/sj.bmt.1704345

20. Kanabar DJ, Attard-Montalto S, Saha V, Kingston JE, Malpas JE, Eden OB (1995) Quality of life in survivors of childhood cancer after megatherapy with autologous bone marrow rescue. Pediatr Hematol Oncol 12(1):29-36 doi:10.3109/08880019509029525 
21. Kolsteren MMP, Koopman HM, Schalekamp G, Mearin ML (2001) Health-related quality of life in children with celiac disease. J Pediatr 138(4):593-595 doi:10.1067/mpd.2001.111504

22. Koopman HM, Theunissen NCM, Vogels AGC, Kamphuis RP, Verrips GH (1998) The DUC-25: a short-form questionnaire for measuring health related quality of life of children with a chronic illness. Qual Life Res 7(7):619

23. Levi RB, Drotar D (1999) Health-related quality of life in childhood cancer: discrepancy in parent-child reports. Int J Cancer Suppl s12:58-64

24. Lof CM, Forinder U, Winiarski J (2007) Risk factors for lower health-related QoL after allogeneic stem cell transplantation in children. Pediatr Transplant 11(2):145-151 doi:10.1111/j.13993046.2006.00630.x

25. Manne S, DuHamel K, Ostroff J, Parsons S, Martini DR, Williams SE et al (2004) Anxiety, depressive, and posttraumatic stress disorders among mothers of pediatric survivors of hematopoietic stem cell transplantation. Pediatrics 113(6):1700-1708 doi:10.1542/peds.113.6.1700

26. Manne S, DuHamel K, Winkel G, Ostroff J, Parsons S, Martini R et al (2003) Perceived partner critical and avoidant behaviors as predictors of anxious and depressive symptoms among mothers of children undergoing hematopoietic stem cell transplantation. J Consult Clin Psychol 71(6):1076-1083 doi:10.1037/0022006X.71.6.1076

27. Manne SL, Lesanics D, Meyers P, Wollner N, Steinherz P, Redd W (1995) Predictors of depressive symptomatology among parents of newly diagnosed children with cancer. J Pediatr Psychol 20(4):491-510 doi:10.1093/jpepsy/20.4.491

28. Matthes-Martin SLM, Ladenstein R, Emminger W, Felsberger C, Topf R, Gadner H et al (1999) Organ toxicity and quality of life after allogeneic bone marrow transplantation in pediatric patients: a single center retrospective analysis. Bone Marrow Transplant 23 (10):1049-1053 doi:10.1038/sj.bmt.1701754

29. McQuellon RP, Russell GB, Rambo TD, Craven BL, Radford J, Perry JJ et al (1998) Quality of life and psychological distress of bone marrow transplant recipients: the 'time trajectory' to recovery over the first year. Bone Marrow Transplant 21(5):477486 doi:10.1038/sj.bmt.1701115

30. Nespoli L, Verri AP, Locatelli F, Bertuggia L, Taibi RM, Burgio GM (1995) The impact of pediatric bone marrow transplantation on quality of life. Qual Life Res 4(3):233-240 doi:10.1007/BF02260862

31. Noll RB, Kupst MJ (2007) Commentary: the psychological impact of pediatric cancer hardiness, the exception or the rule. J Pediatr Psychol 32(9):1089-1098 doi:10.1093/jpepsy/jsm049

32. Parsons SK, Barlowe SE, Levy SL, Supran SE, Kaplan SH (1999) Health-related quality of life in pediatric bone marrow transplant survivors: according to whom. Int J Cancer Suppl s12:46-51
33. Parsons SK, Shih MC, DuHamel KN, Ostroff J, Mayer DK, Austin J et al (2005) Maternal perspectives on children's healthrelated quality of life during the first year after pediatric hematopoietic stem cell transplant. J Pediatr Psychol 31 (10):1100-1115 doi:10.1093/jpepsy/jsj078

35. Phipps S, Dunavant M, Lensing S, Rai SN (2002) Acute healthrelated quality of life in children undergoing stem cell transplant: II. Medical and demographic determinants. Bone Marrow Transplant 29(5):435-442 doi:10.1038/sj.bmt.1703376

35. Phipps S, Dunavant M, Lensing S, Rai SN (2005) Psychosocial predictors of distress in parents of children undergoing stem cell or bone marrow transplantation. J Pediatr Psychol 30(2):139-153 doi:10.1093/jpepsy/jsi002

36. Raat H, Mohangoo AD, Grootenhuis MA (2006) Pediatric healthrelated quality of life questionnaires in clinical trials. Curr Opin Allergy Clin Immunol 6(3):180-185 doi:10.1097/01. all.0000225157.67897.c2

37. Schwartz CE, Sprangers MAG (1999) Methodological approaches for assessing response shift in longitudinal health-related qualityof-life research. Soc Sci Med 48(11):1531-1548 doi:10.1016/ S0277-9536(99)00047-7

38. Socié G, Salooja N, Cohen A, Rovelli A, Carreras E, Locasciulli A et al (2003) Nonmalignant late effects after allogeneic stem cell transplantation. Blood 101(9):3373-3385 doi:10.1182/blood2002-07-2231

39. Streisand R, Rodrigue JR, Houck C, Graham-Pole J, Berlant N (2000) Brief report: parents of children undergoing bone marrow transplantation: documenting stress and piloting a psychological intervention program. J Pediatr Psychol 25(5):331-337 doi:10.1093/jpepsy/25.5.331

40. Sutherland HJ, Fyles GM, Adams G, Hao Y, Lipton JH, Minden MD et al (1997) Quality of life following bone marrow transplantation: a comparison of patient report with population norms. Bone Marrow Transplant 19(11):1129-1136 doi:10.1038/ sj.bmt. 1700806

41. Theunissen NCM, Vogels TGC, Koopman HM, Verrips GH, Zwinderman KA, Verloove-Vanhorick SP et al (1998) The proxy problem: child report versus parent report in health-related quality of life research. Qual Life Res 7(5):387-397 doi:10.1023/ A: 1008801802877

42. Thomas KA, Renaud MT, Depaul D (2004) Use of the parenting stress index in mothers of preterm infants. Adv Neonatal Care 4 (1):33-41 doi:10.1016/j.adnc.2003.11.012

43. Tsimicalis A, Stinson J, Stevens B (2005) Quality of life of children following bone marrow transplantation: critical review of the research literature. Eur J Oncol Nurs 9(3):218-238 doi:10.1016/j.ejon.2004.08.006 